\title{
Educação para a cidadania global: trabalho colaborativo internacional baseado em plataforma digital
}

\author{
Global Citizenship Education: collaborative work supported by digital platform \\ Margarida Fernandes*, Luís Santos** \\ *Agrupamento de Escolas Carlos Amarante, **Universidade do Minho
}

\begin{abstract}
Resumo
A Educação para a Cidadania Global vem emergindo como dimensão importante na cultura de cidadania crítica na escola. Esta comunicação, no âmbito do projeto Conectando Mundos (baseado numa plataforma online), integrado na Rede de Educação para a Cidadania Global (RECG) - uma comunidade de aprendizagem agrupando dezenas de professores de todo o país - avalia a participação dos jovens no projeto, a usabilidade da plataforma e as perceções dos professores envolvidos. Conclui-se que, com limitações, o projeto contribuiu para a tomada de consciência dos jovens sobre as problemáticas sociais tratadas, para desenvolver a RECG, designadamente a dinâmica local associada a esta escola.

Palavras-chave: educação para a cidadania global; plataformas digitais; trabalho colaborativo; rede ECG
\end{abstract}

\begin{abstract}
Global Citizenship Education (GCE) has emerged as an important framework for schools' contribution towards an active and critic citizenship. This paper focuses on a research held with students of a Portuguese school within the international project Connecting Worlds (based on an online digital platform). This was an activity from the Portuguese GCE Network, a community of practice composed by teachers around educational activities focused on global citizenship of tenths of educators and teachers from the whole country. It was sought young participation in the project, the usability of the platform and to know the involved teachers' assessment, and their will to go on again next year. Thus, it was concluded that the Connecting Worlds project contributed to the awareness of young people in relation to addressed social issues, to consolidate and develop the GCE Network, including the local dynamics associated with this school.

Keywords: global citizenship education, digital platforms, collaborative work, GCE network
\end{abstract}

\section{Introdução}

No âmbito da educação, vem suscitando um crescente interesse e atenção em diversos países, reforçados pelo lançamento, em 2012, pelo secretário-geral da ONU da Global Education First Initiative, a Educação para a Cidadania Global (ECG), como resultado de uma crescente consciência de que a educação deve contribuir para a criação de sociedades mais democráticas, mais justas e mais inclusivas.

Por outro lado, vem-se assistindo à emergência, desde há uns anos, de diversas plataformas digitais no âmbito da educação, sejam plataformas polivalentes de uso genérico, como o Moodle ou outras ligadas a editoras, sejam plataformas mais específicas, ligadas a áreas disciplinares ou projetos. É este o caso da plataforma que se encontra no centro deste estudo e que suporta o projeto Conectando Mundos (www.conectandomundos.org), um projeto internacional já com doze anos (Figura 1). Esta proposta educativa, dirigida a todos os alunos do $1^{\circ}$ ao $12^{\circ}$ ano (organizada por faixas etárias), propõe atividades em sala de aula articuladas com iniciativas online numa rede à escala mundial, com a participação efetiva de inúmeros países, sendo os alunos organizados em equipas multinacionais que interagem de forma cooperativa recorrendo a esta plataforma, utilizando uma das oito línguas de trabalho (italiano, castelhano, português, inglês, francês, galego, catalão e basco); a presença de quatro línguas do país vizinho revela a origem do projeto, o qual teve este ano a sua $12^{\mathrm{a}}$ edição.

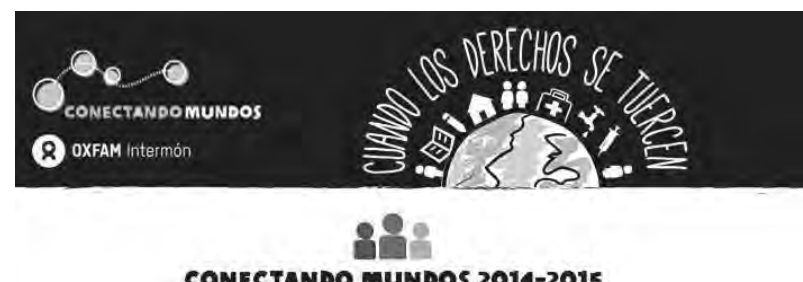

CONECTANDO MUNDOS 2014-2015

DEFESA DOS DIREITOS SOCIAIS UNIVERSAIS

Figura 1. Conectando Mundos 2014-2015

Encontram-se várias definições para a Educação para a Cidadania Global (ECG), consoante as perspetivas. Poderíamos dizer que o cidadão global é aquele que: está ciente da sua pertença a um mundo mais vasto e tem consciência do seu próprio papel como um cidadão do mundo; respeita e valoriza a diversidade; procura compreender como o mundo funciona nos planos económico, político, social, cultural, tecnológico e ambiental; indigna-se com a injustiça social; dispõe-se a agir para tornar o mundo um lugar mais justo e sustentável; participa e contribui para a comunidade a diversos níveis, do local ao global (adapt. de OXFAM, 1997).

A ECG pode definir-se como "um quadro de referência que engloba o modo como a educação pode desenvolver 
o conhecimento, as competências, os valores e as atitudes necessários para assegurar um mundo mais justo, pacífico, tolerante, inclusivo, seguro e sustentável” (adapt. de UNESCO, 2014, p. 5).

Em Portugal, foi aprovada em 2009, pelo Ministério dos Negócios Estrangeiros e pelo Ministério da Educação, a Estratégia Nacional de Educação para o Desenvolvimento (2010-2015), atualmente em reformulação para um novo período (IPAD - Instituto Português de Apoio ao Desenvolvimento, 2010).

Já antes desta data, um grupo de professores/as e educadores/as portugueses/as vinha desenvolvendo iniciativas diversas visando promover a ECG nas escolas, participando em projetos, alguns de âmbito internacional e organizando encontros de reflexão e partilha de experiências. Este trabalho colaborativo conduziu em 2013 à criação de uma Rede de Educação para a Cidadania Global (RECG), uma Comunidade de Prática (CdP), no sentido definido por Wenger: "groups of people who share a concern or a passion for something they do and learn how to do it better as they interact regularly" (2015), ou ainda "a group of people who share a practical challenge, and in the context of interacting regularly, learn from and with each other, how to address the challenge they face. In other words they develop a shared practice” (idem).

Esta comunicação incide sobre uma atividade no âmbito da RECG (2013), o projeto Conectando Mundos (CM), desenvolvido numa escola do ensino básico $\left(5^{\circ}\right.$ ao $9^{\circ}$ ano) do norte de Portugal.

Pretendia apurar-se, com o estudo, se a participação dos jovens no projeto tinha contribuído para uma tomada de consciência em relação aos temas-guia, as aprendizagens relacionadas com esses temas, e a adequação da plataforma digital ao projeto. Adicionalmente, procurou-se avaliar a usabilidade da plataforma. Pretendia, também, saber-se qual a avaliação que os professores envolvidos faziam do projeto, bem como a eventual predisposição para prosseguir no próximo ano. Os dados foram recolhidos pelos métodos de observação (direta e logging do sistema) e inquérito, com a utilização de questionários (previamente validados) e um focus group (visando dar voz aos alunos e esclarecer alguns dos resultados dos questionários). A grande maioria dos alunos avaliou positivamente a usabilidade da plataforma. As opiniões sobre o projeto foram muito positivas (quase sempre superiores a 90\%), sendo menos conseguidos os aspetos ligados à interação com colegas de outros países, por razões que se detalham. Os professores manifestaram um grande entusiasmo pelo projeto e pelo trabalho desenvolvido pelos alunos, e pretendem renovar a participação no próximo ano. Foi, assim, possível concluir-se que o projeto Conectando Mundos contribuiu para a tomada de consciência dos jovens em relação às problemáticas sociais tratadas, além de suscitar um grande entusiasmo, apesar de alguns problemas identificados na plataforma (os quais são descritos e discutidos, incluindo uma avaliação por peritos). Os professores valorizaram, igualmente, o projeto, sublinhando as suas potencialidades para as aprendizagens dos alunos e as respetivas competências de trabalho colaborativo. Contribuiu, igualmente, para consolidar e desenvolver a RECG, designadamente a dinâmica local associada a esta escola, já com alguns anos.

\section{Metodologia}

A metodologia adotada é a de investigação-ação, em que a reflexão crítica se articula com a intervenção no processo, fazendo dos autores simultaneamente investigadores e atores. De acordo com Coutinho (2014, p. 365), quatro palavras caraterizam esta metodologia: "situacional, interventiva, participativa, autoavaliativa". Assim, os atores-autores intervieram num "contexto social específico" (idem), diagnosticando e procurando criar condições de aprendizagem sobre o tema específico da edição do CM deste ano ("Defesa dos Direitos Sociais Universais”); mas não se trata de uma mera caraterização dos conhecimentos ou perceções dos alunos, há uma procura de operar mudanças na sua consciência, de promover projetos e processos participativos que permitam aos envolvidos apropriarem-se desse trabalho e transformarem-se a si próprios, numa avaliação continuada, de reflexão e trabalho colaborativo local e, desejavelmente, global, via plataforma digital.

Após e durante a intervenção, adiante descrita, os dados, numa primeira fase, foram recolhidos através de observação por software logging e de inquérito por questionário, este feito a alunos e professores.

O software logging, de acordo com Carvalho (2001, p. 143), "records the interaction between the user and the educational software”, permitindo analisar as interações dos alunos com a plataforma online e as suas respostas.

Os questionários foram previamente validados, de modo duplo: por peritos (duas peritas, ambas com larga experiência na utilização de questionários em áreas afins da ECG, uma com 62 anos e dirigente de ONGD há mais de 40 anos, especialista em Educação para o Desenvolvimento [ED]; a segunda, de 31 anos, técnica superior em ONG, responsável por projetos de ED/ECG) e por população análoga (turma do mesmo ano de escolaridade, com caraterísticas semelhantes), e eram constituídos por total de 20 questões, utilizando uma escala do tipo Likert (1932), em que o 1 corresponde ao "DISCORDO TOTALMENTE" е о 5 ao "CONCORDO TOTALMENTE”.

A amostra dos alunos que responderam aos questionários online era constituída por 46 alunos da escola referida, distribuídos por duas turmas do $9^{\circ}$ ano de escolaridade, com idades compreendidas entre os 14-16 anos (média de 14.6), correspondentes a 69\% do universo. No caso dos professores, a amostra de era constituída por 7 professoras (idade média de 48 anos), correspondentes a $50 \%$ de todos os professores que trabalharam com as turmas no projeto (só 1 masculino).

No sentido de completar a informação, foi realizado, na fase final, um focus group com 25 alunos de uma das turmas que participantes no CM. O focus group "visa explorar perceções, experiências ou significados de um grupo de pessoas que têm alguma experiência ou conhecimento em comum” (Coutinho, 2014, p. 143).

Muñoz e Sánchez referem-se a uma experiência anterior, semelhante à que descrevemos e no âmbito do mesmo projeto, mas com alunos mais novos, do $1^{\circ}$ ciclo, e com diferenças metodológicas, salientando o "elevadísimo grado de motivación del alumnado; alto grado de 
consecución de los objetivos propuestos, sobrepasando incluso nuestras expectativas iniciales” (2014, p. 9).

\section{A sala no mundo e o mundo na sala}

Inserido numa das dinâmicas locais da RECG, foi lançado o desafio a um conjunto de professore/as da referida escola do norte de Portugal ( $2^{\circ}$ e $3^{\circ}$ ciclos) para trabalharem com os seus alunos as temáticas da proposta educativa CM. Num encontro de trabalho com este conjunto de educadores/as foi realçada a importância de se usarem as metodologias e as temáticas propostas pelo $\mathrm{CM}$, tal como referidas na sua página web: "promover o diálogo intercultural entre crianças e jovens de diferentes ambientes sociais e geográficos”; criar um espaço de trabalho colaborativo baseado no lema "«pensar globalmente, agir localmente», utilizando as TIC (Tecnologias da Informação e Comunicação) para possibilitar o conhecimento mútuo e promover a partilha de realidades diferentes e problemas comuns"; partindo da reflexão sobre os ambientes próximos e sobre o que sabemos das realidades dos outros participantes, "tornarmo-nos conscientes da realidade dos outros países” (Conectando Mundos, 2015). Passando esta fase inicial, os professores, nas primeiras reuniões pedagógicas do início do ano letivo, incentivaram outros colegas a aderir ao grupo de trabalho que se estava a constituir, o que iria favorecer o trabalho partilhado entre os professores com o mesmo grupo de alunos. O grupo inicial começou a crescer e de 8 passou a 14 professores que aderiram ao CM. Os responsáveis internacionais disponibilizaram materiais na plataforma digital online do CM, para que cada professor pudesse alicerçar os seus conhecimentos sobre a temática que iria ser abordada ("Defesa dos Direitos Sociais Universais”) e, posteriormente deu-se início ao trabalho com os alunos, que durou todo o segundo período letivo, dividido em quatro fases. Cada uma das fases tinha tarefas definidas para serem superadas pelos alunos através de trabalho de pesquisa (leitura de notícias sobre a realidade atual, artigos de opinião, páginas web oficiais de várias organizações, etc.), construção colaborativa de textos e outros materiais, debates interpares, utilização dos vários espaços disponibilizados na referida plataforma digital (fóruns, espaços para colocação dos materiais construídos, textos para aprofundamento do tema, etc.).

As questões-problema que foram colocadas, em cada fase do projeto, foram um estímulo para os alunos. Incentivou-os a procurarem mais informações sobre a realidade de países que ainda pouco tinham ouvido falar. Tomaram consciência sobre as dificuldades que algumas populações têm no acesso a direitos básicos como a educação, a saúde, o trabalho, etc. Confrontaram estas realidades com a realidade do seu país, debateram as semelhanças e as diferenças entre o que se passa não só na sua cidade e no seu país, e o que se passa em diferentes países e diferentes continentes. No final do projeto concluíram que agora estavam mais atentos ao que se passava à sua volta, utilizavam até alguns dos temas debatidos na turma para os debater com a família e com os amigos.

\section{Resultados obtidos e discussão}

Os questionários apresentam valores bastante altos na concordância em relação às questões colocadas (só 3 com valor médio < 4.0), como se pode ver na Figura 3. A correspondência entre os códigos das perguntas do gráfico e o respetivo texto pode ser vista na Figura 3.

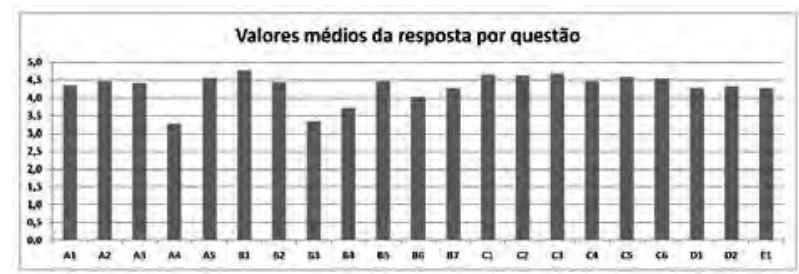

Figura 2. Valores médios da resposta por questão

As questões que obtiveram uma menor pontuação foram: A4 - Utilizei a plataforma digital para mostrar informação a amigos ou família;

B3 - Trocar ideias com alunos doutros países;

B4 - Refletir com a família e/ou amigos sobre problemas do mundo atual.

O facto de haver pouca interação com colegas estrangeiros dever-se-á à barreira da língua. As respostas quanto ao envolvimento da família são algo contraditórias com os comentários do focus group, embora se possa admitir que neste contexto se terão pronunciado os que mais dialogaram com a família.

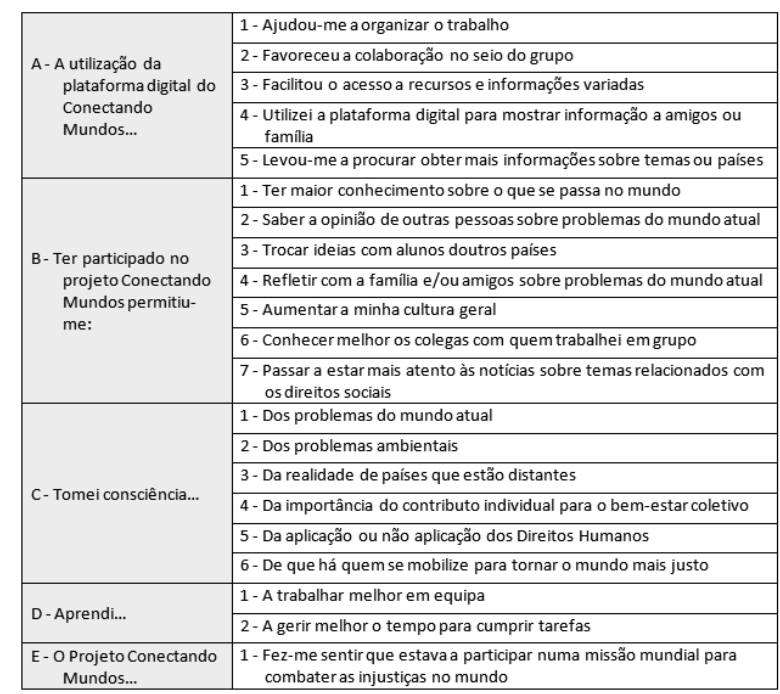

Figura 3. Lista de questões com referência

Destacamos algumas das questões, pela especial relevância, e por terem merecido comentários durante o focus group, como veremos.

Assim, na Tabela 1, verificamos que os alunos, sem exceção, concordam que melhoraram a sua informação sobre os temas tratados e os países envolvidos, o que não surpreende, dada a sua juventude. A Tabela 2 mostra os resultado de uma questão relacionada, mas que remete para uma visão mais global sobre os acontecimentos mundiais. 
Tabela 1.

A utilização da plataforma do CM levou-me a procurar obter mais informações sobre temas ou países (A5)

\begin{tabular}{lrr}
\hline \multicolumn{1}{c}{ Nível de concordância } & $\%$ & $\mathrm{~N}^{\circ}$ respostas \\
\hline Concordo totalmente & 57 & 26 \\
Concordo & 43 & 20 \\
Não tenho opinião & 0 & 0 \\
Discordo & 0 & 0 \\
Discordo totalmente & 0 & 0 \\
\hline
\end{tabular}

Tabela 2.

Ter participado no CM permitiu-me ter maior conhecimento sobre o que se passa no mundo (B1)

\begin{tabular}{lrr}
\hline \multicolumn{1}{c}{ Nível de concordância } & $\%$ & $\mathrm{~N}^{\circ}$ respostas \\
\hline Concordo totalmente & 76 & 35 \\
Concordo & 24 & 11 \\
Não tenho opinião & 2 & 1 \\
Discordo & 0 & 0 \\
Discordo totalmente & 0 & 0 \\
\hline
\end{tabular}

Conseguiam verbalizar ideias/opiniões que, por vezes, em confronto com as ideias dos outros, acabavam por reformular, assim como fortalecer as competências de escuta do outro, como resulta da Tabela 3 e das opiniões expressas no focus group.

Tabela 3.

Ter participado no CM permitiu-me saber a opinião de outras pessoas sobre problemas do mundo atual (B2)

\begin{tabular}{lrr}
\hline \multicolumn{1}{c}{ Nível de concordância } & $\%$ & $\mathrm{~N}^{\circ}$ respostas \\
\hline Concordo totalmente & 52 & 24 \\
Concordo & 41 & 19 \\
Não tenho opinião & 4 & 2 \\
Discordo & 2 & 1 \\
Discordo totalmente & 2 & 0 \\
\hline
\end{tabular}

Uma dimensão importante e que, enquanto educadores/as, nos interessava valorizar e avaliar, era a do trabalho colaborativo, em que se verifica uma grande concordância em relação a uma melhor competência para o trabalho em equipa (Tabela 4).

Tabela 4.

Aprendi a trabalhar melhor em equipa (D1)

\begin{tabular}{lrr}
\hline \multicolumn{1}{c}{ Nível de concordância } & $\%$ & $\mathrm{~N}^{\mathrm{o}}$ respostas \\
\hline Concordo totalmente & 37 & 17 \\
Concordo & 59 & 27 \\
Não tenho opinião & 2 & 1 \\
Discordo & 0 & 0 \\
Discordo totalmente & 2 & 1 \\
\hline
\end{tabular}

Apesar de os alunos não terem interagido com os colegas estrangeiros, como inicialmente previsto, acabaram por ler alguns dos materiais que aqueles colocavam na plataforma. Este facto foi por eles considerado uma mais-valia, pois foram confrontados com outras perspetivas de resolução dos mesmos desafios que lhes tinham sido colocados. Poder-se-ia questionar de os alunos não tiveram uma interpretação restritiva quanto ao "trocar ideias”, já que, sem ter havido interação, houve a recolha (por parte dos dois lados?) de informações e opiniões.

Foram recolhidas pelo método de inquérito, através da técnica de focus froup, as razões apontadas pelos alunos para esta situação: sentiam que não estavam a falar com ninguém em particular mas apenas com uma entidade abstrata. A participação nos espaços de conversação, na plataforma digital em uso no CM, é feita através de um utilizador coletivo, a turma na sua totalidade (para cada uma é apenas disponibilizada um acesso). O facto de não entenderem a língua dos colegas estrangeiros também foi apontado como entrave, não confiaram nos tradutores online, pois temiam que as mensagens fossem deturpadas.

Os alunos consideraram muito positiva a participação no CM. Para eles significou um espaço de liberdade: eram-lhes fornecidos materiais apelativos que os ajudava a organizarem o trabalho de grupo, lhes colocava questões que eles, apesar de nunca terem pensado nelas, conseguiam perceber que estavam relacionadas com a sua vida e a vida dos que os rodeiam. Ficaram sensibilizados para a procura de um melhor conhecimento da realidade de outros países e de problemáticas sobre as quais nunca tinham refletido. Os alunos transpuseram as paredes da sala de aula e passaram a estar mais atentos aos problemas que afligem não só o seu país como também alguns países sobre os quais sabiam pouco.

Além disso os temas que debatiam na sala de aula eram, por vezes, também abordados em contexto de família ou de roda de amigos.

Os professores, de áreas de docência muito variadas, manifestaram unanimemente, na resposta ao questionário, a intenção de participar novamente no projeto, atendendo ao que consideraram ter sido os bons resultados obtidos. A plataforma pareceu-lhes simples (86\%) e de fácil acesso (100\%), os materiais adequados ao tema (100\%), mas nem tanto à idade (71\%), os desafios apropriados (71\%), mas a maioria pensa crê que o prazo foi curto (86\%).

Os aspetos mais valorizados pelos professores foram:

- O entusiasmo dos alunos;

- O contacto dos alunos com realidades diferentes;

- A visão e abertura para o mundo;

- O despertar da consciência cívica e da noção do valor da intervenção social;

- A sensibilização dos alunos para as desigualdades.

Os professores manifestaram uma grande satisfação pelo desenvolvimento da RECG na sua escola, e pela expressão que a Rede tem vindo a adquirir à escala nacional, com a presença de cerca de centena e meia de presenças no recente Encontro Nacional.

Como referido, foi feita uma análise da usabilidade da plataforma do CM, envolvendo, uma vez mais, peritos, população análoga e o público-alvo (6 alunos); De acordo com Nielsen (2000), bastariam 5 utilizadores para garantir qualidade ao processo. Para o efeito, foi usado um questionário de satisfação SUS (System Usability Scale) de Brooke (1986) em papel (adapt. de Oliveira, 2014). Do questionário SUS, os resultados, calculados pelo processo indicado por Brooke (1986), conduziram a um valor médio de 85.8 pontos, com um intervalo [75,95]. De acordo com Bangor, Kortum, e Miller (2009, p. 121), um resultado acima dos 70 seria aceitável, e, dentro do sistema letter grade anglo-saxónico, 85.8 
equivaleria a um $\mathrm{B}$, excellent. Assim, conclui-se destes resultados que o resultado é um excellent, mas ainda algo abaixo do best imaginable.

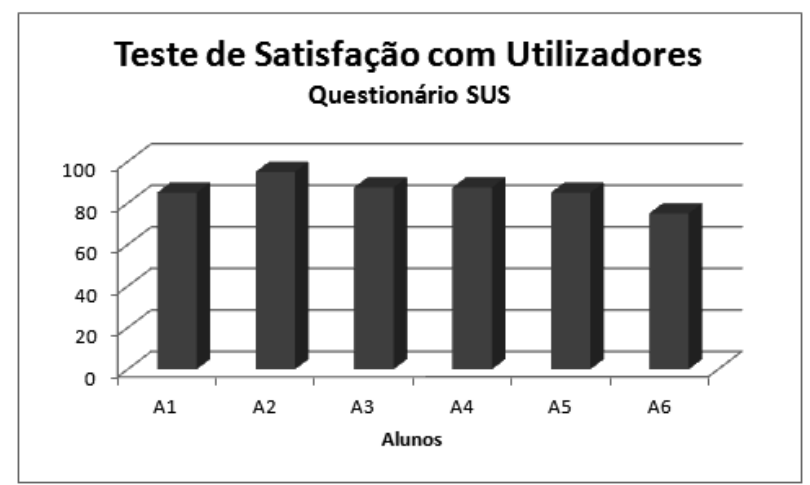

Figura 4. Respostas ao questionário SUS

\section{Conclusões}

Do ponto de vista da usabilidade, parece que a plataforma responde razoavelmente, sem dificuldades de maior. No entanto, levantam-se problemas relacionados com o acesso único coletivo e a falta de individualização, referida pelos alunos, além de potenciais problemas de segurança conhecidos, mas não tratados neste trabalho, a merecerem uma futura atenção.

Os alunos conseguiram desenvolver os trabalhos propostos, e manifestaram grande satisfação com o processo, tendo os resultados, quer pela sua avaliação, quer pela dos professores, sido muito positivos; de sublinhar a consciência crítica acrescida em relação a um problema de candente atualidade. $\mathrm{O}$ aspeto menos conseguido, a merecer atenção em anos subsequentes, será o da barreira da língua, o que poderá ser ultrapassado envolvendo professores destas áreas.

Os professores expressaram o seu apreço pelo projeto a dois níveis: por um lado, pelo modo diferente de trabalhar em sala de aula com os alunos e pelos resultados obtidos; por outro, pelas perspetivas de expansão e consolidação da RECG, enquanto comunidade de prática.

Algumas das limitações deste estudo decorreram de boa parte dos professores envolvidos estarem pela primeira vez a trabalhar no âmbito do CM, havendo, assim, lugar para melhorias na recolha de informação e na documentação de todo o projeto.

\section{Referências}

Bangor, A., Kortum, P., \& Miller, J. (2009). Determining What Individual SUS Scores Mean: Adding an Adjective Rating Scale. Journal of Usability Studies, 4, 114-123.

Brooke, J. (1986). SUS - A 'quick and dirty' usability scale. In P. W. Jordan, B. Thomas, B. A. Weerdmeester, \& I. L. McClelland (Eds.), Usability Evaluation in Industry (pp. 189-194). London: Taylor and Francis.

Carvalho, A. A. (2001). Usability Testing of Educational Software: methods, techniques and evaluators. Actas do $3^{\circ}$ Simpósio Internacional de Informática Educativa: CD-ROM.
Conectando Mundos. (2015). Conectando Mundos. Obtido em http://www.conectandomundos.org/pt/ presentacion

Coutinho, C. P. (2014). Metodologia de Investigação em Ciências Sociais: Teoria e Prática (2a ed.). Coimbra: Almedina.

IPAD - Instituto Português de Apoio ao Desenvolvimento. (2010). Estratégia Nacional de Educação para o Desenvolvimento. Lisboa: IPAD.

Likert, R. (1932). A Technique for the Measurement of Attitudes. Archives of Psychology, 140, 1-55.

Muñoz, J. A. T., \& Sánchez, J. M. P. (2014). Conectando mundos. Paper presented at the I Congreso Andaluz "Escuela Transformadora", Málaga. http://www.researchgate.net/profile/Jose_Tellez2/public ation/270578545_Conectando_mundos/links/54ae936d0 cf2b48e8ed44d07.pdf

Nielsen, J. (2000). Why You Only Need to Test with 5 Users. Obtido em http://www.nngroup.com/ articles/ why-you-only-need-to-test-with-5-users/

Oliveira, D. (2014). Estudo da usabilidade em sistemas web para tablet. (Master), FEUP, Porto.

OXFAM. (1997). A curriculum for global citizenship. Oxford: OXFAM.

RECG. (2013). Referencial da Rede Educação para a Cidadania Global. Obtido em http://www.cidac.pt/ files/6813/8920/1990/Referencial_REde_ECG_v.final.p $\mathrm{df}$

UNESCO. (2014). Global Citizenship Education: Preparing learners for the challenges of the twenty-first century. Paris.

Wenger, E. (2015). Communities of practice - a brief introduction. Obtido em Wenger-Trayner website: http://wenger-trayner.com/introduction-to-com munities-of-practice/ 